\title{
Influence of mentalis muscle relaxation on oronasal breathing
}

\author{
Mara Letícia Gobbis ${ }^{1}$ \\ https://orcid.org/0000-0002-5325-4595 \\ Bruno Luis Amoroso Borges ${ }^{2}$ \\ https://orcid.org/0000-0003-4927-5761 \\ Karina Aparecida Tramont $\mathrm{i}^{3}$ \\ https://orcid.org/0000-0002-1788-1508 \\ Cynthia Lopes da Silva ${ }^{1}$ \\ https://orcid.org/0000-0001-8065-3754 \\ Mirian Hideko Nagae ${ }^{1}$ \\ https://orcid.org/0000-0002-2401-5317
}

\begin{abstract}
Universidade de Campinas - UNICAMP, Faculdade de Ciências Médicas - FCM Campinas, São Paulo, Brasil.

2 Centro Universitário de Jaguariúna UNIFAJ, Jaguariúna, São Paulo, Brasil, Colégio Brasileiro de Osteopatia, Campinas, São Paulo.

${ }^{3}$ Clínica Premium Care e Acallanto, Setor de Fonoaudiologia, São Paulo, Brasil.
\end{abstract}

Conflict of interests: Nonexistent

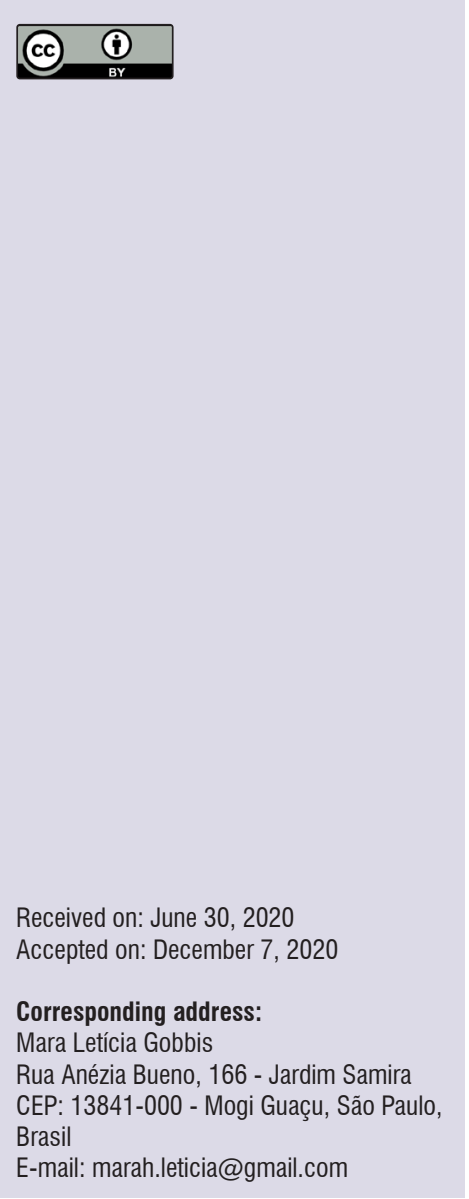

\section{ABSTRACT}

Purpose: to investigate the existence of changes in the electromyographic patterns of the mentalis and inferior orbicularis oris muscles in oronasal breathers, submitted to massage therapy on the mentalis muscle.

Methods: a controlled blind placebo experiment, with a sample of 19 oronasal breathers (1 man and 18 women), mean age (standard deviation) 22.3 (2.63) years, randomly divided into control and experimental groups, respectively with 7 and 12 volunteers. The experimental group alone underwent myotherapy with massages for 3 months, while electromyographic data were collected from both groups at the beginning and end of the treatment, both at rest and when swallowing water. The analysis of variance was conducted to test the existence of differences between the means; the $5 \%$ significance level was used.

Results: the analysis of variance revealed signs of interaction between the group and phase effects when analyzing the root mean square values of both the inferior orbicularis oris and the mentalis muscles. As expected, no signs of significant differences were found between the means of the phases in the control group. On the other hand, signs of significant difference were found in the experimental group, with reduced root mean square values in both muscles. The inferior orbicularis oris muscle, which in the pre-phase had a mean (standard deviation) of 202.10 (161.47) $\mu \mathrm{V}$, had, in the post-phase, values of $131.49(159.18) \mu \mathrm{V}$. The mentalis muscle, in its turn, had in the pre- and post-phase, respectively, a mean (standard deviation) of 199.31 (279.77) $\mu \mathrm{V}$ and 114.58 (253.56) $\mu \mathrm{V}$.

Conclusion: given that no effect was detected in the control group, the decrease in the root mean square values of the mentalis and inferior orbicularis oris muscles in oronasal breathers was attributed to the massage therapy on the mentalis muscle.

Keywords: Mouth Breathing; Massage; Electromyography; Myofunctional Therapy; Chin 


\section{INTRODUCTION}

Breathing is indispensable to humans because it provides the necessary gas exchange that nourishes the tissues. However, if the nasal breathing function is somehow hindered, a mouth breathing pattern may be used, which might cause various impairments, such as postural changes, protruded shoulders, straight cervical spine, flexed head and neck; behavioral disorders, such as restlessness, irritation, restless sleep; inexpressive face with infraorbital dark circles; physiological disorders, such as nocturnal enuresis, day sleepiness; and learning disorders with inattention and lack of memory, despite a normal intelligence ${ }^{1-3}$. Hence, various authors already consider it a syndrome, named mouth-breathing syndrome (MBS) ${ }^{4,5}$.

There are different causes of MBS, including hypertrophy of the palatine and/or pharyngeal tonsils, nasal septum deviation, excessive retrognathism antagonizing the upper arch against the lower lip, hypertrophic turbinates, rhinitis, tumor, polyps, nasal fractures ${ }^{1-5}$. Given the impairments that may result from it and as it is already considered a public health issue $e^{4,5}$, drug and/or surgical treatments have been used to clear the upper airways ${ }^{5}$.

Once the causes of mouth breathing are solved, it is not uncommon to find oronasal breathing, a condition resulting from either a vicious habit or a preserved muscle memory ${ }^{5,6}$. However, such a situation is not always given due attention, possibly because it is often related to chronic conditions whose treatment is difficult and require continuous control (such as allergic rhinitis), and because of the assumption that oronasal breathing does not influence the difference between intra- and extraoral pressure and does not compromise the muscular system ${ }^{5-9}$.

Electromyographic studies have already proved the similarity between the mouth and oronasal breathers ${ }^{10}$ in their suprahyoid and orbicularis oris muscles, both at rest and in functions such as swallowing. Thus, there may be difficulties in dental and/or skeletal corrections, besides possible treatment relapses, because of the influence of musculature throughout the dental and maxillo-mandibular development in the stomatognathic system $^{10}$. In such cases, myotherapy is essential to lip closure.

The orbicularis oris is an important muscle, responsible for lip closure ${ }^{11,12}$. Made up of its superior and inferior parts, it is common to observe a shortened upper lip and an everted lower lip in mouth-breathers, due to the flaccidity of such musculature ${ }^{8}$. Felício ${ }^{13}$ reports that, when the lips are ajar, "they do not restrain the dental arches and then the upper teeth are often buccally displaced, making lip closure even more difficult. Thus, lips ajar reduce sensory impulses and consequently decrease the motor impulses that would make the upper lip hypotrophic, and the lower one, flaccid"13.

Beneath the inferior orbicularis oris muscle, there is another one that may hinder its activity, the mentalis muscle. Some authors consider the mentalis not properly a lip muscle but one that controls the lips, as it helps to position the lower lip due to its slightly vertical anatomical disposition, which favors the adequate positioning of the lower lip ${ }^{11,12}$. In clinical practice, even the simple palpation of the mentalis muscle insertion often stimulates lip closure in cases of ajar mouth.

In the literature ${ }^{3,14}$, the intense mentalis muscle activity in mouth-breathers has been well described ${ }^{10,15-20}$. In this regard, due to flaccidity of the inferior orbicularis oris muscle, it is supposed that the mentalis muscle remains hyperactive to compensate it and favor lip closure. However, such hyperactivity may lead to an increase in volume and shorten the musculature, everting the lip even further and making the antagonization of the upper and lower lips more difficult.

Muscle therapies have been indicated to strengthen the orbicularis oris muscle and effectuate nasal breathing. In these cases, though, the previous relaxation of the mentalis muscle may help strengthen the inferior orbicularis oris muscle. Massage maneuvers on the mentalis muscle, besides decreasing its volume, may also help improve the disposition of its fibers and hence effectively strengthen the orbicularis oris muscle ${ }^{13}$.

In the literature, papers are scarce in the field of speech-language-hearing studying techniques such as massage therapy, particularly regarding the mentalis muscle, although this intervention is already known ${ }^{21}$ and clinically used in mouth-breathing patients.

Massage has been described since 1952 by authors such as Beard and cited by Biasotto 22 as "manipulating the soft tissues with the hands to generate effects that will impact the nervous, muscle, and respiratory systems, besides blood flow and the local and general lymphatic system". These manipulations have curative, prophylactic, and invigorating purposes ${ }^{22,23}$, especially indicated when there are structural changes in the muscle tissues. The relaxation brought about by massage is "manifested as an increase in muscle 
length and direct stimulus of the Golgi tendon organ, spreading through the activation of the inhibitory reflex of the muscle being massaged"23. In the case of the mentalis muscle, massage therapy is very appropriate because the aim is to normalize its muscular behavior and strengthen the orbicularis oris muscle.

In speech-language-hearing therapy, to deal with cases of muscle impairment, resources such as palpation, visual inspection, and professional opinion are commonly used. However, these resources are subjective. Thanks to technological advancements, a series of instruments allowed for a clearer and more objective view of the actual condition of the musculature. One of them is the surface electromyography (EMG), which registers the electrical properties of the muscles, helps understand the muscle functions and changes, and above all provides the means to a precise measurement of the conditions of the stomatognathic system $^{24,25}$. It is the noninvasive, painless, quick, and objective gold standard.

This study aimed to investigate the existence of changes in the electromyographic patterns of the mentalis and orbicularis oris muscles in oronasal breathers submitted to massage therapy on the mentalis muscle. In the research, the EMG may furnish data on the response to the muscle condition with the approached therapy.

\section{METHODS}

The study was approved by the Research Ethics Committee of the Universidade Estadual de Campinas (University of Campinas - UNICAMP), São Paulo, Brazil, under no. 61582716.5.0000.5404, in compliance with Resolution 466/12 of the Conselho Nacional de Saúde (National Health Council - CNS). It was carried out in the Electromyography Laboratory of the CEPRE/ FCM/UNICAMP. The participants were involved in the activities of the research only after formally consenting to it through the informed consent form (ICF).

\section{Sample}

The sample comprised 19 participants - college students and employees of the institution of origin - subdivided into Control Group (CG), with seven participants, and Experimental Group (EG), with 12 participants. Their age ranged from 18 to 27 years, both males and females. The participants that would and would not undergo massage therapy were randomly chosen.
- Inclusion criteria: being over 18 years old; having a medical record and a report from the otorhinolaryngologist of the Hospital of the institution of origin and/or CECOM (Community Health Center) confirming they had been oronasal breathers for more than 3 months; not having their upper airways obstructed.

- Exclusion criteria: being younger than 18 years; being a nasal breather; having neurological impairments; taking myorelaxant and/or analgesic drugs; being in dentoskeletal Angle Class II, Division 1, or Class III; having upper arch antagonistic to lower lip with maxillo-mandibular overjet; having upper arch overjet hindering lip closure; having a face trauma; having a history of fibromyalgia; having a beard or hair in the perioral region.

\section{Procedures}

Before beginning the electromyographic analyses, the participants filled in a registration form for future contact. Two electromyographic assessments were conducted in both groups, one in the beginning and the other after 3 months of myotherapy. Only the experimental group was instructed to have their mentalis muscle massaged.

The electromyography was conducted in compliance with the European Applications of Surface Electromyography (SENIAM). The data was collected with a Myosystem BR1 electromyograph with 12-bit resolution analog-to-digital card, common-mode rejection ratio (CMRR) of $60 \mathrm{~dB}$, BioPak software, version 7.2. The surface electrodes used were disposable circular $\mathrm{Ag} / \mathrm{AgCl}$ bipolar passive ones manufactured by Meditrace Kendall-LTP, model Chicopee MA01. Before the electromyography, the participants had their skin cleaned with fat-free vegetable soap and $70 \%$ ethyl alcohol to better fix the electrodes and reduce skin impedance. The participants were seated on a comfortable chair, their feet on the floor and head parallel to the ground according to Frankfurt plane, eyes open looking straight ahead. A circular stainless-steel ground electrode, $2 \mathrm{~mm}$ in diameter, was lubricated with conductive gel and fixed on the participant's forehead. The bipolar electrodes were fixed on the inferior orbicularis oris muscle, 1 $\mathrm{cm}$ away from each other, on each side of the median line, $2 \mathrm{~mm}$ above the free edge of the lip, and on the mentalis muscle on the region of the chin, on each side of the median line. The electrodes' input channels were 
the same for all collections, to standardize the electromyographic signal pick-up.

The signal was picked up with a sampling frequency of $4000 \mathrm{~Hz}$, and the screen signal amplification was adjusted with a maximum gain of 150 to 400 times, so that the signal occupied two thirds of the screen, during the 5-second rest.

The electromyographic data were recorded during the rest, maintaining the usual position of the lips, and swallowing water - for which, the participants were given a disposable plastic cup with approximately 20 $\mathrm{ml}$ of water. They were then instructed to hold within the mouth a minimum amount of water, which they should swallow at once when asked so by the researcher.

Following data collection, the signals were filtered with a band-pass filter of $20 \mathrm{~Hz}$ to $500 \mathrm{~Hz}$, rectified and submitted to a low-pass filter of 2 to $4 \mathrm{~Hz}$ to obtain the linear envelopment. After data processing, they were converted to TXT language to calculate the mean electrical activity of the signal with the root mean square (RMS).

\section{Massage Therapy}

After the initial electromyography, the EG participants were shown how to do the massage therapy, massage technique ${ }^{26}$, at the Electromyography Laboratory of the institution of origin. This manipulation is done with the fingertips apprehending the muscle in intermittent compression and decompression circular motions, moving the skin and subcutaneous tissues over the underlying structures ${ }^{26}$.

They were instructed to perform it comfortably seated on an armless chair, their feet on the floor, and looking straight ahead. The procedure should be repeated once a week, for 5 to 10 minutes, or until they felt the muscle released ${ }^{27,28}$. The estimated manipulation time was based on an excerpt of the Therapy Protocol, item 2.2, used by Felício et al. ${ }^{29}$.
The EG participants were also instructed to take note on a qualitative follow-up sheet, after each session for 3 months, registering the week when the massage took place, date, time, duration, and their perception about the massage. They were sent weekly reminders via WhatsApp ${ }^{\circledR}$ not to forget to do the massages.

\section{Statistical Analysis}

The analysis of variance was applied based on the fitting of a generalized mixed linear model for two-factor experiments (Group and Phase) and the interaction between the main effects. The analysis of variance was complemented with Student's t-test for multiple comparisons of significant interaction mean values. The $5 \%$ significance level $(p<0.05)$ was used in all the statistical tests, and the calculations were made with support from the SAS system.

\section{RESULTS \\ Sample characterization}

The sample comprised 19 participants - seven in the $C G$ and 12 in the $E G$ - mean age 22.3 ( \pm 2.625 ) years; one of them was male, and 18 , females. The sample was representative because the individual electromyographic values were not much disparate and characterized distinct and well-outlined profiles in each group.

\section{Surface Electromyography}

In a preliminary study of the Phases (pre and post) in the $C G$ and $E G$ of the inferior orbicularis oris and mentalis muscles, both at rest and swallowing, a satisfactory adherence of the residues was verified in the Gaussian distribution. Thus, the statistical analysis was based on normal distribution; then, the analysis of variance was conducted.

Based on Table 1, it was investigated whether there was an interaction between Groups and Phases. 
Table 1. Analysis of variance for root mean square values of the inferior orbicularis oris and mentalis muscles, both at rest and swallowing

\begin{tabular}{cccccc}
\hline \multirow{2}{*}{ Condition/Muscle } & \multicolumn{2}{c}{ Fitting } & \multicolumn{3}{c}{ F-statistics (p-value) } \\
\cline { 2 - 6 } & Distribution & DF (Num,Den) & Group & Phase & Group*Phase \\
\hline $\begin{array}{c}\text { At rest } \\
\begin{array}{c}\text { Inferior orbicularis } \\
\text { oris }\end{array}\end{array}$ Lognormal & $(1.17)$ & $0.79(0.3856)$ & $1.62(0.2202)$ & $6.68(0.0193)$ \\
Mentalis & Lognormal & $(1.17)$ & $0.29(0.5945)$ & $0.27(0.6080)$ & $5.92(0.0263)$ \\
\hline $\begin{array}{c}\text { Swallowing } \\
\text { Inferior orbicularis } \\
\text { oris }\end{array}$ & Lognormal & $(1.17)$ & $1.31(0.2679)$ & $0.15(0.7057)$ & $6.66(0.0194)$ \\
Mentalis & Lognormal & $(1.17)$ & $0.90(0.3557)$ & $2.05(0.1717)$ & $6.55(0.0210)$ \\
\hline
\end{tabular}

Captions: DF - Degrees of Freedom; Num - numerator; Den - denominator; significant difference - *interaction significant effect $(p<0.05)$.

The above data reveal the existence of a significant effect of the interaction Group/Phase $(p<0.05)$. For this analysis, the control and experimental groups were joined; hence, it was necessary to use the t-test to compare the means of the effects, two by two, since the analysis of variance only informs the existence of the interaction effect. In other words, there is a difference between at least two means of the four compared ones, although it is not possible to conclude which means are significantly different one from the other. To facilitate the understanding, each condition (rest and swallowing) was treated in separate topics.

Table 2 presents statistics that allow for the comparison of the means of the Group and Phase combinations, of the RMS obtained at rest.

Table 2. Mean (standard deviation) and t-test comparing the root mean square values of the studied muscles in the groups and phases combinations $(\alpha=0.05)$ at rest

\begin{tabular}{ccc}
\hline \multirow{2}{*}{ Group - Phase } & \multicolumn{2}{c}{ Muscles } \\
\cline { 2 - 3 } & Inferior orbicularis oris & Mentalis \\
\hline Experimental - Pre & $202.10(161.47) \mathrm{A}$ & $199.31(279.77) \mathrm{A}$ \\
Experimental - Post & $131.49(159.18) \mathrm{B}$ & $114.58(253.56) \mathrm{B}$ \\
Control - Pre & $75.14(43.43) \mathrm{AB}$ & $53.08(26.12) \mathrm{AB}$ \\
Control - Post & $105.31(70.69) \mathrm{AB}$ & $185.84(247.47) \mathrm{AB}$ \\
\hline
\end{tabular}

Means with equal letters do not differ from one another in the t-test with a $5 \%$ significance level.

In the case of both the inferior orbicularis oris and mentalis muscles, differences are observed within the $E G$, as the post-phase values were reduced in relation to those of the pre-phase, as shown in Figure 1.
Table 3 presents statistics that make it possible to compare the means of the Group and Phase combinations, of the RMS in swallowing. 


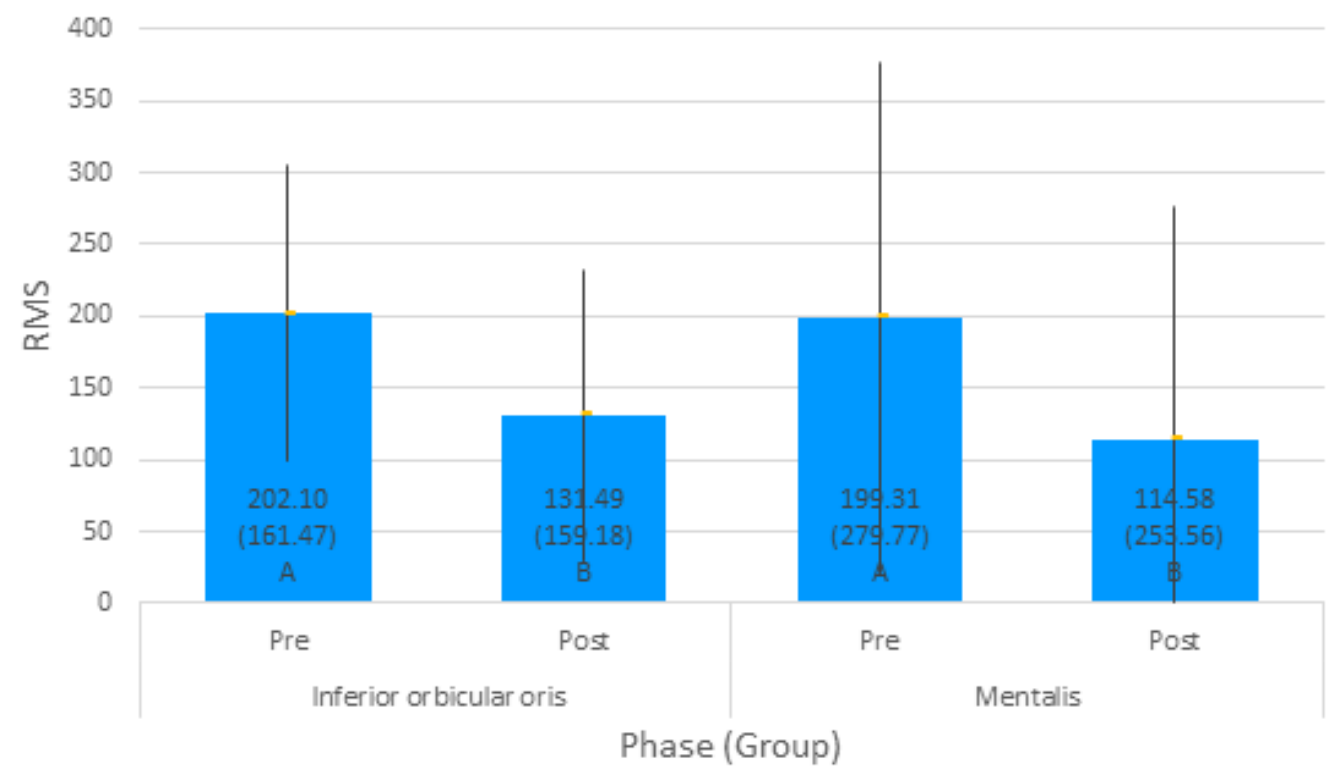

Means with equal letters do not differ from one another in the t-test with a $5 \%$ significance level.

Figure 1. Mean (standard deviation) and 95\% confidence limits for the mean root mean square of the inferior orbicularis oris and mentalis muscles, in the pre- and post-phase

Table 3. Mean (standard deviation) and t-test comparing the root mean square values of the studied muscles in the groups and phases combinations $(\alpha=0.05)$ in swallowing

\begin{tabular}{ccc}
\hline \multirow{2}{*}{ Group - Phase } & \multicolumn{2}{c}{ Muscles } \\
\cline { 2 - 3 } & Inferior orbicularis oris & Inferior orbicularis oris \\
\hline Experimental - Pre & $754.69(897.94) \mathrm{A}$ & $400.54(564.29) \mathrm{A}$ \\
Experimental - Post & $448.99(565.20) \mathrm{B}$ & $120.98(246.14) \mathrm{B}$ \\
Control - Pre & $177.09(164.80) \mathrm{AB}$ & $137.88(84.33) \mathrm{AB}$ \\
Control - Post & $248.90(148.80) \mathrm{AB}$ & $223.57(183.66) \mathrm{A}$ \\
\hline
\end{tabular}

Means with equal letters do not differ from one another in the t-test with a $5 \%$ significance level.

When swallowing, signs of difference are perceived in the inferior orbicularis oris muscle between the preand post-phase in the EG, as depicted in Figure 2.
Lastly, it is observed concerning the mentalis muscle that the RMS mean value was significantly smaller in EG/post-phase than in EG/pre-phase and $\mathrm{CG} /$ post-phase, as shown in Figure 3. 


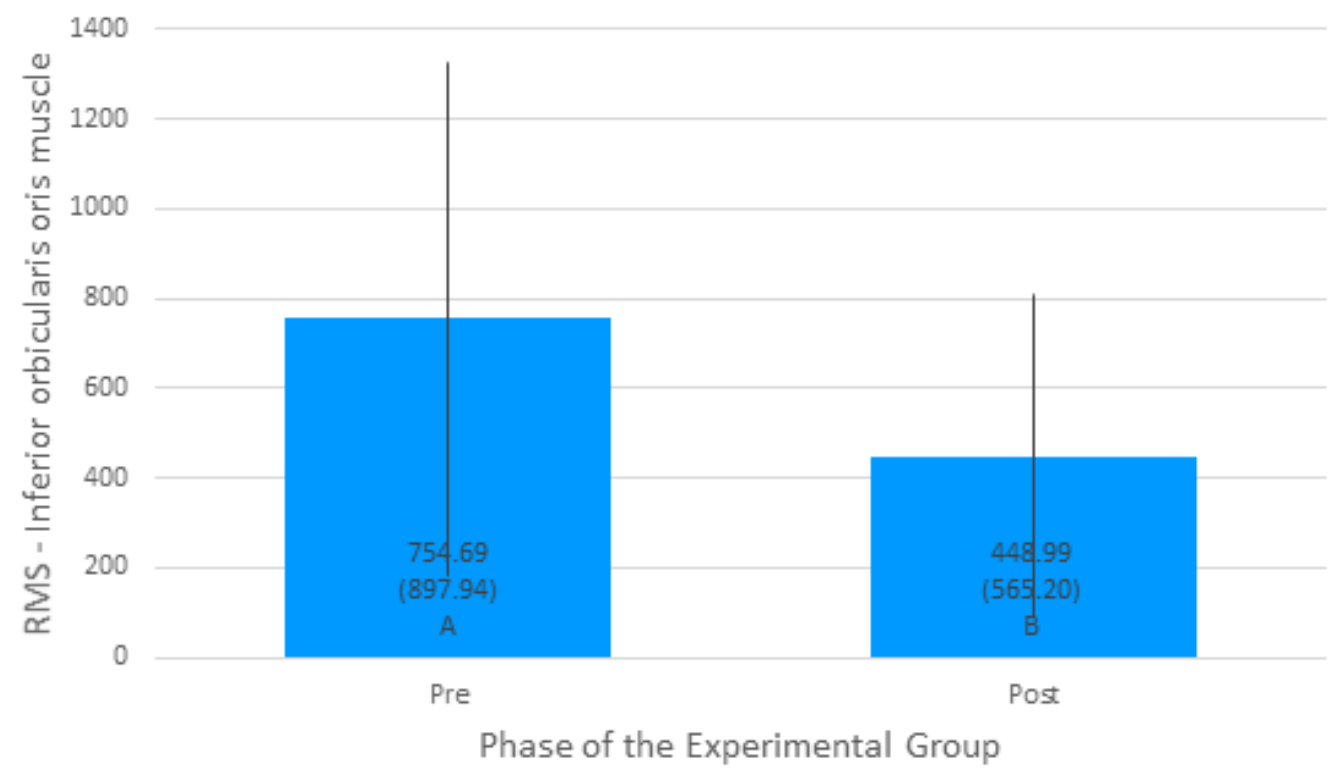

Means with equal letters do not differ from one another in the t-test with a 5\% significance level.

Figure 2. Mean (standard deviation) and 95\% confidence limits for the mean of root mean square of the inferior orbicularis oris muscle obtained in swallowing, in the experimental group

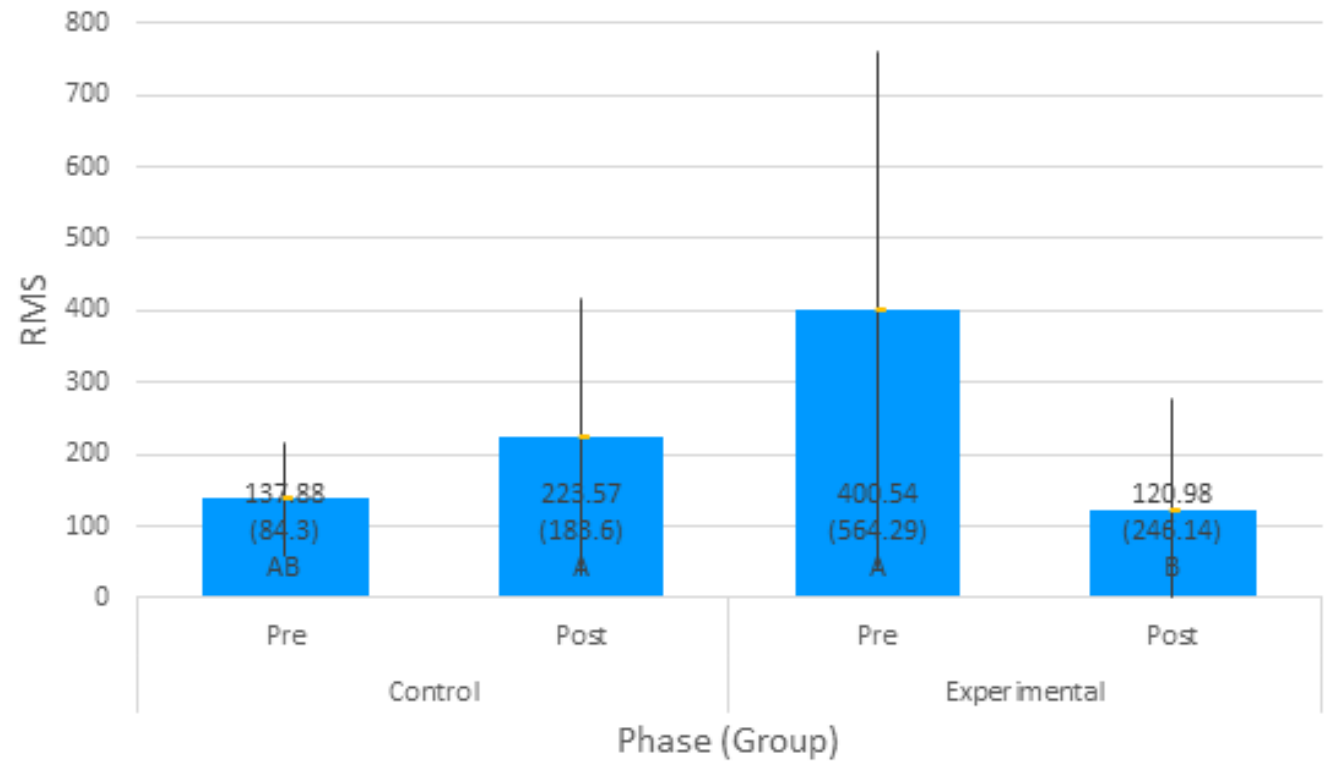

Means with equal letters do not differ from one another in the t-test with a $5 \%$ significance level.

Figure 3. Mean (standard deviation) and 95\% confidence limits for the mean of root mean square of the mentalis muscle obtained in swallowing

\section{DISCUSSION}

This study investigated whether massage therapy on the mentalis muscle influences the inferior orbicularis oris muscle in oronasal breathers, in a sample of healthy young people, mean age $22.3( \pm 2.63)$ years, with no morphological changes that could maintain oronasal breathing. It was an important factor to consider, as the etiology in these cases (muscular instead of mechanical) agrees with the literature, which reports that the difficulty in lip closure is due to maintaining the vicious habit and/or muscle memory ${ }^{10}$. In such cases, even after solving what caused the 
obstruction, the muscle involved does not always change in the new condition.

The strategy used - mentalis muscle relaxation in oronasal breathers, either submitted or not to the intervention - initially verified an interaction between Group (Control and Experimental) and Phase (pre and post), as seen in Table 1, at rest and swallowing. In Table 2, it was observed that the interaction occurred only in EG - i.e., the myotherapy influenced the musculature, both in the static and dynamic conditions. Various factors may have contributed to these results, including the 3-month duration proposed, as in the literature this is normally the time necessary for the muscle fibers to recompose ${ }^{30,31}$. Another aspect was the manner how it was performed: manually and by the own participant, which may have favored their sensitive perception.

At rest, the RMS electromyographic records that assessed the mean electrical activity verified a significant decrease in activity in both the mentalis and the inferior orbicularis oris muscles (Figure 1). These data prove that the myotherapy, performed only on the mentalis muscle, influenced the inferior orbicularis oris muscle as well. The values obtained, although still far from reaching the normal standard of $5 \mu \mathrm{V}^{32,33}$, indicate that the musculature went in the expected direction - i.e., decreased activity. Myotherapies, such as stretching the superior orbicularis oris muscle, are probably still necessary to ensure a better-balanced system $^{34}$. However, achieving muscle changes at rest is a remarkable gain, considering that muscle inadequacy in this state is more harmful than when performing functions such as swallowing ${ }^{35}$. This is so because the muscle tone at rest is maintained for longer than those required by functional situations.

The results were also reinforced in swallowing, with less electrical activity observed (Figure 2) in the mentalis and inferior orbicularis oris muscles, which is in line with their accessory function. However, the values obtained in swallowing were higher than at rest, which is coherent with the situation that demands more muscle effort (Table 3). These data, according to authors such as Mattos ${ }^{10}$, Tomé \& Marchiori ${ }^{36}$, Schievano $^{37}$, and Marchesan ${ }^{38}$ characterize atypical swallowing, since they are not due to a deviated morphology, but to a vicious muscle condition or a preserved memory. It is important to highlight that, in the cases of atypical swallowing, the adjacent or accessory muscles that participate in the function are as important as those of the tongue because lip closure is essential to the correct positioning and tone of the tongue muscles. But, for it to happen, the perioral musculature must be properly and evenly positioned. We swallow approximately 2,400 to 2,600 times $^{39}$ a day, which makes this function indispensable not only to children's dentoskeletal development but also to adults' effective orthodontic treatments because muscle movement is one of the main factors of both growth direction and dental positioning ${ }^{38,39}$.

Different from what took place at rest, the CG in swallowing significantly increased the activity of the mentalis muscle after 3 months (Table 3 and Figure 3 ). This result may have occurred because of the place and time when the data were collected, as it was the time of sugarcane harvest in the region and the fires are routine. This situation leads to acuter nasal allergies, making lip closure more difficult and consequently causing greater hypertrophy of the mentalis muscle.

The findings of the study prove that the inferior orbicularis oris muscle, even if not submitted to any intervention, changed its behavior due to the relaxation maneuvers performed on the mentalis muscle. This may be related to the insertion of the mentalis muscle, which is right beneath the lips, where the orbicularis oris muscle is located. In other words, as the insertion is a movable point (differently from the origin, which is fixed), when the mentalis muscle is contracted, the orbicularis oris muscle is moved as well.

Thus, significant results were obtained with the oronasal breathers, especially regarding the decreased activity of the inferior orbicularis oris muscle, whose values are in line with a normal standard at rest, as it does not need to work, and in swallowing, as it only has a secondary function in lip closure. Hence, myotherapy, when justified and properly applied, enables the muscle fiber to change toward the normal standard ${ }^{34,35}$.

\section{CONCLUSION}

Given that no effect was detected in the CG, the decrease in RMS means of the mentalis and inferior orbicularis oris muscles in oronasal breathers was attributed to massage therapy on the mentalis muscle. Based on these results, it is concluded that, in their relationship, the mentalis muscle indeed interferes with the inferior orbicularis oris muscle, as its activity decreased after the myotherapy. 


\section{REFERENCES}

1. Veron HL, Antunes AG, Milanesi JV, Correa ECR. Implications of mouth breathing on the pulmonary function and respiratory muscles. Rev. CEFAC. 2016;18(1):242-51.

2. Batista DPF, Bagarollo MF. Surface electromyography in orofacial and cervical musculature in mouth breathing children: an integrative literature review. Rev. CEFAC. 2020;22(1):e19318.

3. Siqueira VCV, Sousa MA, Bérzin F, Casarini CAS. Análise eletromiográfica do músculo orbicular da boca em jovens com Classe II, 1a divisão, e jovens com oclusão normal. Dental Press J. Orthod. 2011;16(5):54-61.

4. Nagae MH, Alves MC, Kinoshita RL, Bittencourt ZZLC, Gagliardo H. Quality of life in mouth and mouth breathers. Rev. CEFAC. 2013;15(1):105-10.

5. Neiva PD, Kirkwood RN, Mendes PL, Zabjek K, Becker HG, Mathur S. Postural disorders in mouth breathing children: a systematic review. Braz J Phys Ther. 2018;22(1):7-19.

6. Lee S-Y, Guilleminault C, Chiu H-Y, Sullivan SS. Mouth breathing, "nasal disuse," and pediatric sleep-disordered breathing. Sleep Breath. 2015;19(4):1257-64.

7. Ribeiro GC, Dos Santos ID, Santos AC, Paranhos LR, César CP. Influence of the breathing pattern on the learning process: a systematic review of literature. Braz J Otorhinolaryngol. 2016;82(4):466-78.

8. Imbaud TC, Mallozi MC, Domingos VB, Solé D. Frequency of rhinitis and orofacial disorders in patients with dental malocclusion. Rev Paul Pediatr. 2016;34(2):184-8.

9. Knösel M, Jung K, Kinzinger G, Buss O, Engelke W. A controlled evaluation of oral screen effects on intra-oral pressure curve characteristics. Eur. J. Orthod. 2010;32(5):535-41.

10. Mattos FMGF, Bérzin F, Nagae MH. The impact of oronasal breathing on perioral musculature. Rev. CEFAC. 2017;19(6):801-11.

11. Drake RL, Vogi W, Mitchell AWM. Gray's - Anatomia para Estudantes. 3. a edition, Rio de Janeiro: Elsevier; 2005.

12. Brodie AG. Muscular factors in the diagnosis and treatment of malocclusions. Angle Orthod.1953;23(2):71-7.

13. Felício CM. Fonoaudiologia aplicada a casos odontológicos - motricidade oral e audiologia. São Paulo: Pancast; 1999.
14. Malhotra S, Gupta V, Pandey RK, Singh SK, Nagar A. Dental consequences of mouth breathing in the pediatric age group. Int $\mathrm{J}$ Oral Health Sci. 2013;3(2):79-83.

15. Engelke W, Jung K, Knösel M. Intra-oral compartment pressure: a biofunctional model and experimental measurements under different conditions of posture. Clin. Oral Investig. 2011;15(2):165-76.

16. Marx R. The circum-oral muscles and the incisor relationship: an electromyographic study. Eur. j. orthod. 1965;41:187-201.

17. Dei A, Miyamoto JJ, Takada J, Ono T, Moriyama $\mathrm{K}$. Evaluation of blood flow and electromyographic activity in the perioral muscles. Eur $\mathrm{J}$ Orthod. 2016;38(5):525-31.

18. Moyers R. Handbook of orthodontics for the students and general practitioner. Chicago: Year Book Medical Publishers; 1973.

19. Nicolet C, Muñoz D, Marino A, Werner A, Argandoña J. Lip competence in Class III patients undergoing orthognathic surgery: an electromyographic study. J Oral Maxillofac Surg. 2012;70(5):e331-6.

20. Dixit UB, Shetty RM. Comparison of soft-tissue, dental, and skeletal characteristics in children with and without tongue thrusting habit. Contemp Clin Dent. 2013;4(1):2-6.

21. Gallo J, Campiotto AR. Terapia miofuncional orofacial em crianças respiradoras orais. Rev. CEFAC. 2009;11(3):305-10.

22. Biasotto DA. Estudo eletromiográfico dos músculos do sistema estomatognático durante a mastigação de diferentes materiais [dissertação]. Piracicaba (SP): Universidade Estadual de Campinas, Faculdade de Odontologia de Piracicaba; 2000.

23. Goldberg J, Sullivan SJ, Seaborne DE. The effect of two intensities of massage on H-Reflex amplitude. Phys Ther. 1992;72(6):449-57.

24. Nagae M, Bérzin F. Electromyography: applied in the phonoaudiology clinic. Braz $\mathrm{J}$ Oral Sci. 2004;3(10):506-9.

25. Busanello-Stella AR, Blanco-Dutra AP, Corrêa ECR, da Silva AMT. Electromyographic fatigue of orbicular oris muscles during exercises in mouth and nasal breathing children. CoDAS. 2015;27(1):80-8.

26. Abreu MF, Souza TF, Fagundes DF. Os efeitos da massoterapia sobre o estresse físico e psicológico. Rev. FAEMA. 2012;3(1):101-5. 
27. Di Grazia RC. Avaliação da aplicação do Método Mulligan e massoterapia classica nas disfunções da articulação temporomandibular em mulheres adultas por meio da escala visual-numerica de dor e pelo SF-36 [tese]. Campinas (SP): Universidade Estadual de Campinas, Faculdade de Ciências Médicas; 2009.

28. Nagae M, Bérzin F, Alves MC, Bérzin MGR. How the anterior, middle and posterior portions of the temporalis muscle work during mastication. Braz. J. Oral Sci. 2011;10(3):213-6.

29. Felício CM, Melchior MO, Silva MAMR. Effects of orofacial myofunctional therapy on temporomandibular disorders. Cranio. 2010;28(4):249-59.

30. Castroflorio T, Farina D, Bottin A, Piancino $M G$, Bracco P, Merletti R. Surface EMG of jaw elevator muscles: effect of electrode location and inter $\square$ electrode distance. J Oral Rehabil. 2005;32(6):411-7.

31. Kalliainen LK, Jejurikar SS, Liang LW, Urbanchek MG, Kuzon WM. A specific force deficit exists in skeletal muscle after partial denervation. Muscle \& Nerve: Official. Muscle Nerve Suppl. 2002;25(1):31-8.

32. Soderberg GL, Knutson LM. A guide for use and interpretation of kinesiologic electromyographic data. Physical therapy. 2000;80(5):485-98.

33. Knutson MMML, Soderberg GL, Ballantyne BT, Clarke WR. A study of various normalization procedures for within day EMG data. J Electromyogr Kinesiol. 1994;4(1):47-59.

34. Campiotto AR. Atuação fonoaudiológica nos distúrbios miofuncionais orofaciais. In: Lopes Filho O (ed). Novo Tratado de Fonoaudiologia. 3a ed. Barueri: Manole; 2013. p. 487-92.

35. Souza DRD, Semechini TA, Kröll LB, Berzin F. Oral myofunctional and electromyographic evaluation of the anterior suprahyoid muscles and tongue thrust in patients with Class II/ 1 malocclusion submitted to first premolar extraction. J. Appl. Oral Sci. 2007;15(1):24-8.

36. Tomé MC, Marchiori SC. EMG study of the orbicularis oris muscles in nose and mouth breathing children during rest with and without lip sealing. J Bras Ortod Ortop Facial. 1998;3(15):59-66.
37. Schievano D, Rontani RMP, Berzin F. Influence of myofunctional therapy on the perioral muscles. Clinical electromyographic evaluations. J. Oral Rehabil. 1999;26(7):264-9.

38. Marchesan IQ. Deglutição: diagnóstico e possibilidades terapêuticas. In: Marchesan IQ (org). Fundamentos em Fonoaudiologia - aspectos clínicos da motricidade oral. 2a ${ }^{a}$ ed. Rio de Janeiro: Guanabara Koogan, 2005. p. 51-8.

39. D'Onofrio L. Oral dysfunction as a cause of malocclusion. Orthod Craniofac Res. 2019;22(Suppl 1):43-8. 